\title{
Regulation of C6 glioma cell migration by thymol
}

\author{
KANG PA LEE ${ }^{1}$, JAI-EUN KIM ${ }^{2}$, WON-HWAN PARK ${ }^{3}$ and HEEOK HONG ${ }^{4}$ \\ ${ }^{1}$ Department of Physiology, School of Medicine, Konkuk University, Seoul 143-701; \\ Departments of ${ }^{2}$ Pathology and ${ }^{3}$ Diagnostics, College of Korean Medicine, Dongguk University, Goyang 410-820; \\ ${ }^{4}$ Department of Medical Science, School of Medicine, Konkuk University, Seoul 143-701, Republic of Korea
}

Received March 12, 2015; Accepted January 18, 2016

DOI: $10.3892 / 01.2016 .4237$

\begin{abstract}
Tumor cell motility exhibits a crucial role in tumor development. Therefore, the present study aimed to investigate whether thymol could reduce C6 glioma cell migration. Cell viability was determined using the EZ-Cytox Cell Viability kit. The scratch wound healing and Boyden chamber assays were performed to test $\mathrm{C} 6$ glioma cell migration in the presence of fetal bovine serum (FBS). Additionally, the study investigated whether signaling proteins relevant to C6 glioma cell migration, i.e., extracellular signal-regulated kinases (ERK)1/2, protein kinase $\mathrm{C} \alpha(\mathrm{PKC} \alpha)$, matrix metallopeptidase (MMP) 9 and MMP2, were affected by thymol treatment. Up to $30 \mu \mathrm{M}$, thymol did not alter cell viability, whereas $100 \mu \mathrm{M}$ thymol induced the death of $20 \%$ of the cells. Furthermore, thymol $(30 \mu \mathrm{M})$ significantly reduced FBS-induced migration. In the FBS-stimulated C6 glioma cells, thymol $(30 \mu \mathrm{M})$ suppressed PKC $\alpha$ and ERK1/2 phosphorylation. MMP9 and MMP2 production was also significantly reduced by treatment with $30 \mu \mathrm{M}$ thymol in the C6 glioma cells. Taken together, these results indicate that thymol attenuates $\mathrm{C} 6$ glioma cell migration. Additionally, the study suggests that the effect of thymol on the FBS-induced migration of C6 glioma cells affects PKC $\alpha$ and ERK1/2 signaling, and suppresses MMP9 and MMP2 production.
\end{abstract}

\section{Introduction}

Brain tumors are characterized by the presence of malignant tissues within the skull and central spinal canal. Between 2008 and 2012 in the USA, the annual age-adjusted average

Correspondence to: Professor Won-Hwan Park, Department of Diagnostics, College of Korean Medicine, Dongguk University, Dongguk-Ro 32, Goyang 410-820, Republic of Korea

E-mail: diapwh@dongguk.ac.kr

Professor Heeok Hong, Department of Medical Science, School of Medicine, Konkuk University, 120 Neungdong-ro, Gwangjin-gu, Seoul 143-701, Republic of Korea

E-mail: hhong@kku.ac.kr

Key words: C6 glioma, extracellular signal-regulated kinases 1/2, matrix metallopeptidase, protein kinase $\mathrm{C} \alpha$, thymol incidence rate for all primary brain and central nervous system tumors was 21.98 per 100,000 individuals (7.23 malignant; 14.75 benign), and 356,858 brain tumors (117,023 malignant; 239,835 benign) were reported during this time (1). Gliomas are the most common primary brain tumor, accounting for $\sim 81 \%$ of malignant brain tumors (2). Between 2008 and 2012, the annual age-adjusted average incidence rate of this type of brain tumor was 5.83 per 100,000 individuals (1). A characteristic of glioma is that it spreads rapidly to normal brain areas so that the boundary between normal tissue and the tumor becomes indistinct (3). In particular, it has the highest mortality rate due to its specialized feature of rapid cell migration or invasion that cannot be controlled by either surgery or irradiation $(4,5)$. Thus, patients with this brain disease have an average survival rate of 1 year from the time of tumor development.

Moreover, the diagnosis and treatment of glioma are difficult, its pathology and pattern of invasion and migration are poorly understood $(6,7)$. Several studies have reported that the pathological response of glioma, which is the malignant process of infiltration into the extensive normal tissue, is due to the activation of mitogen-activated protein kinase (MAPK), protein kinase $\mathrm{C} \alpha(\mathrm{PKC} \alpha)$ and matrix metalloproteinases (MMPs) (8-11). The MAPK family consists of three types of kinases, p38 MAPK, Jun N-terminal kinase and extracellular signal-regulated kinase 1/2 (ERK1/2), which are involved in cell migration and the growth of the majority of cancer cell types (12). Notably, ERK1/2 phosphorylation is involved in the cell invasion, migration and motility coupled with the progression of brain cancer $(13,14)$. Activation of PKC $\alpha$ is also implicated in the migration of glioma cells (15). MMPs are extracellular endopeptidases involved in motility and invasion $(16,17)$.

Currently, numerous researchers are seeking novel antioxidant and anticancer agents derived from plants. Thymol is a component of a number of essential oils and is known for its anti-inflammatory, anticancer and anti-bacterial effects (18). Studies on essential oils extracted from a variety of plants have shown that they possess great nutritional value, and significant biochemical and physiological activities (18). These beneficial properties have been put to use in the development of functional and medicinal foods. The present study was performed to investigate the effect of thymol on glioma cell migration to determine whether it may have potential in glioma prevention and treatment. 


\section{Materials and methods}

Reagents. Thymol, cell culture materials and the EZ-Cytox Cell Viability Assay kit were purchased from Sigma-Aldrich (St. Louis, MO, USA), Thermo Fisher Scientific (Gaithersburg, MD, USA) and Daeil Lab Services Co., Ltd. (Seoul, Korea), respectively. Rabbit polyclonal anti-rat anti-PKC $\alpha$ (catalog no., \#2056), rabbit polyclonal anti-rat anti-phosphorylated (P)-PKC $\alpha$ (catalog no., \#9375) and rabbit polyclonal anti-rat anti-glyceraldehyde 3-phosphate dehydrogenase (catalog no., \#2118) antibodies were obtained from Cell Signaling Technology Inc. (Beverly, MA, USA). Other antibodies, such as rabbit polyclonal anti-rat anti-ERK1/2 (catalog no., sc-94), mouse monoclonal anti-rat anti-P-ERK1/2 (catalog no., sc-7383), rabbit polyclonal anti-rat anti-MMP2 (catalog no., sc-10736) and goat polyclonal anti-rat anti-MMP9 (catalog no., sc-6840), were purchased from Santa Cruz Biotechnology Inc. (Dallas, TX, USA). All other chemicals were purchased from Sigma-Aldrich.

Cell culture and viability assay. Rat C6 glioma cells were obtained from the Korean Cell Line Bank (Seoul, Korea) and were cultured in Dulbecco's modified Eagle's medium (DMEM) containing 10\% fetal bovine serum (FBS) and 1\% penicillin-streptomycin at $37^{\circ} \mathrm{C}$ in a $5 \% \mathrm{CO}_{2}$ atmosphere. The C6 glioma cells were seeded at $5 \times 10^{4}$ cells/well in a 96 -well microplate containing DMEM and incubated for $24 \mathrm{~h}$. The cells were then incubated with different concentrations $(0$, $0.1,0.3,1,3,10,30,100$ and $200 \mu \mathrm{M}$ ) of thymol in FBS-free medium for $24 \mathrm{~h}$. Cell viability was then determined using an EZ-Cytox Cell Viability Assay kit according to the manufacturer's protocol. The cell viability of thymol-treated cells was determined relative to that of control cells by measuring the absorbance at $450 \mathrm{~nm}$.

Scratch wound healing assay. The C6 glioma cells were seeded at a density of $1 \times 10^{5}$ cells $/ \mathrm{ml}$ in a six-well plate and incubated in $10 \%$ FBS-containing medium for $24 \mathrm{~h}$. These cells were then placed in serum-free medium for $24 \mathrm{~h}$. The scratch wound was made by scratching the center of each well with a $200-\mu 1$ sterile pipette tip to form a cross. This was followed by incubation with or without thymol $(0,3,10$ and $30 \mu \mathrm{m}$ ) in serum-containing medium for an additional $24 \mathrm{~h}$. Images of the cells that migrated into the cell-free scratch wound area were acquired using an inverted microscope (IX71; Olympus Corp., Tokyo, Japan) and analyzed using Image J software (National Institutes of Health, Bethesda, MD, USA).

Boyden chamber assay. To determine the effect of thymol on the migration of the $\mathrm{C} 6$ glioma cells, a Boyden chamber assay was performed in a 48 -well chemotaxis chamber (Neuro-Probe, Gaithersburg, MD, USA), as previously described (19). Briefly, an absence or presence of thymol (3-30 $\mu \mathrm{M}$ ) in DMEM containing 10\% FBS were loaded into the lower chamber. The lower chamber was covered by a polycarbonate filter membrane (pore size, $8 \mu \mathrm{m}$ ) that was coated with $0.1 \%$ collagen type-I (BD Biosciences, Franklin Lakes, $\mathrm{NJ}$, USA). C6 glioma cells $\left(1 \times 10^{6}\right.$ cells $\left./ \mathrm{ml}\right)$ were loaded into the upper chamber. Following incubation at $37^{\circ} \mathrm{C}$ in $5 \% \mathrm{CO}_{2}$ for $90 \mathrm{~min}$, the cells on the lower surface of the membrane were fixed and stained using Diff-Quick (Baxter Healthcare, Deerfield, IL, USA). The cells that had migrated through the membrane were imaged and counted under an inverted microscope (IX71; Olympus Corporation, Tokyo, Japan).

Gelatin zymography. To determine the activity of gelatinases, such as MMP2 and MMP9, in the thymol-treated C6 glioma cells, a gelatin zymography assay was performed, as previously described (8). Briefly, to test the gelatin zymography, samples of cultured media supernatant from C6 glioma cells were collected. Samples ( $30 \mu \mathrm{l})$ were loaded onto a $8 \%$ sodium dodecyl sulfate-polyacrylamide electrophoresis gel containing $0.2 \%$ gelatin (WELGENE, Daegu, South Korea). Following electrophoresis, the gel was incubated with $2.5 \%$ Triton X-100 (Sigma-Aldrich) and agitated. Following incubation at $37^{\circ} \mathrm{C}$ for $24 \mathrm{~h}$, the gel was stained using Coomassie Brilliant Blue R 250 (Sigma-Aldrich). Stained bands were visualized and quantified using Image $\mathbf{J}$ software.

Western blot analysis. To determine the expression of proteins associated with the migration of C6 glioma cells, western blotting was performed with specific antibodies. Briefly, $20 \mu \mathrm{g}$ of protein was prepared from each treatment group. Once the proteins had been boiled at $100^{\circ} \mathrm{C}$ for $10 \mathrm{~min}$, they were separated by electrophoresis on $12 \%$ acrylamide gels and then transferred onto polyvinylidene difluoride membranes (Amersham Pharmacia Biotech, Piscataway, NJ, USA) in transfer buffer at $4^{\circ} \mathrm{C}$ for $2 \mathrm{~h}$. The membranes were blocked in 5\% bovine serum albumin in Tris-buffered saline (TBS) at room temperature for $1 \mathrm{~h}$ and then washed in TBS with $0.1 \%$ Tween 20 (TBS/T). Subsequently, the membranes were incubated overnight at $4^{\circ} \mathrm{C}$ with antibodies against P-ERK1/2 and P-PKC $\alpha$, total ERK1/2 (T-ERK1/2) and PKC (T-PKC), MMP9 and MMP2 (all 1:1,000 dilution). The membranes were washed with TBS/T, followed by incubation with donkey anti-goat immunoglobulin (Ig) G (catalog no., sc-2033; Santa Cruz Biotechnology, Inc.), horse anti-mouse IgG (catalog no., 7076; Cell Signaling Technology, Inc.) or goat anti-rabbit IgG (catalog no., 7074; Cell Signaling Technology, Inc.) horseradish peroxidase-conjugated secondary antibodies (all 1:1,000 dilution). The protein expression levels were analyzed via electrochemiluminescence (ECL plus kit; Amersham Pharmacia Biotech). The protein bands were visualized and quantified using Image J Software.

Statistical analysis. The results are expressed as the mean \pm standard error of at least three independent experiments. The differences between the test groups were examined using a one-way analysis of variance followed by Tukey's test. $\mathrm{P}<0.05$ was considered to indicate a statistically significant difference. Statistical analysis was performed with GraphPad Prism 4.0 software (GraphPad Software Inc., San Diego, CA, USA).

\section{Results}

Effect of thymol on C6 glioma cell viability. The chemical structure of thymol is presented in Fig. 1A. Thymol cytotoxicity was tested by treating C6 glioma cells with different 
A<smiles>Cc1ccc(C(C)C)c(O)c1</smiles>

B

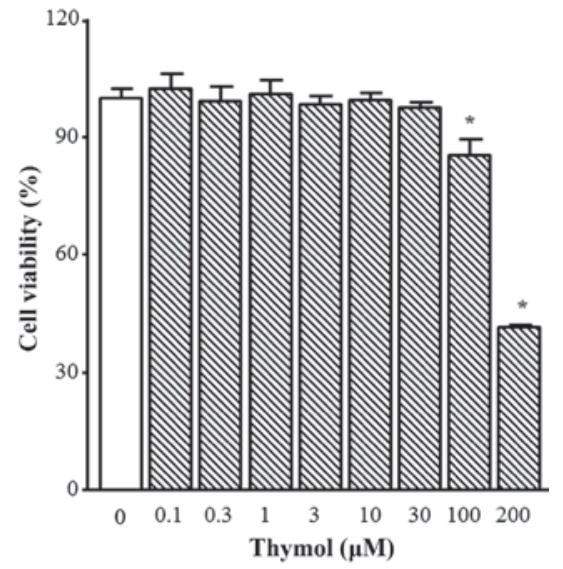

Figure 1. Effect of thymol on C6 glioma cell viability. (A) Chemical structure of thymol. (B) Effect of thymol on C6 glioma cell viability. The C6 cells were cultured in serum-free medium in the presence of thymol (0.1-200 $\mu \mathrm{M})$ for $24 \mathrm{~h}$. Post-treatment cell viability was determined using a 2,3-bis[2-methyloxy-4nitro-5-sulfophenyl]-2H-tetrazolium-5-carboxanilide assay. Data are expressed as the mean \pm standard error $(\mathrm{n}=3$ ). Cell viability in the absence of thymol is expressed as $100 \%$. ${ }^{*} \mathrm{P}<0.05$ vs. control (no thymol).

A

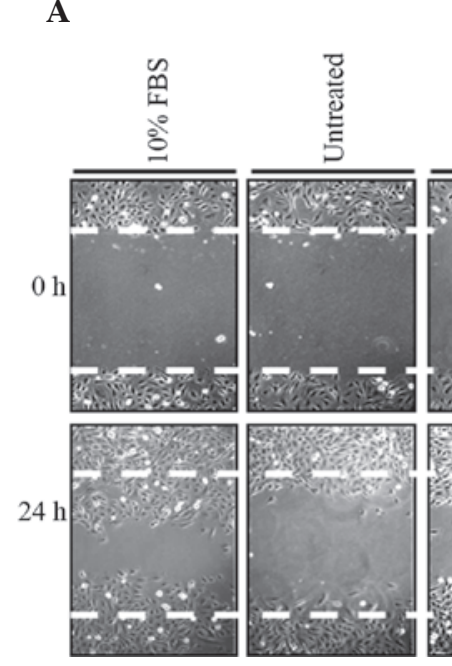

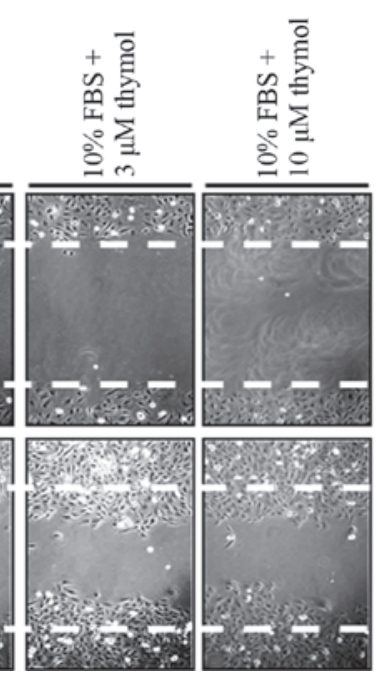

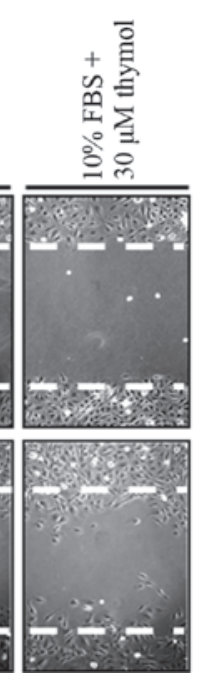

B

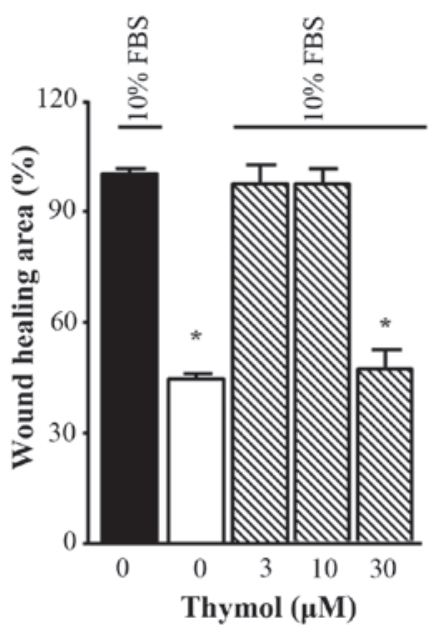

Figure 2. Effect of thymol treatment on the scratch wound healing migration of C6 glioma cells. C6 glioma cells were cultured in serum-free medium for $24 \mathrm{~h}$ and then scratched using a sterilized $200-\mu \mathrm{l}$ pipette tip. The cells were cultured in the absence or presence of thymol (3-30 $\mu \mathrm{M})$ for $1 \mathrm{~h}$ and then exposed to $10 \%$ FBS for $24 \mathrm{~h}$. (A) The scratch distance at time 0 (the white dotted line in the upper panel) was used for normalization and the closed distance at $24 \mathrm{~h}$ (lower panel) was used for wound healing assay. (B) The vertical axis represents the relative healing (\%) of the wounded region. Data are expressed as the mean \pm standard error $(\mathrm{n}=3)$. Wound healing in presence of treatment (FBS alone) is expressed as $100 \% .{ }^{*} \mathrm{P}<0.05$ vs. FBS stimulation without thymol. FBS, fetal bovine serum.

concentrations $(0.1-200 \mu \mathrm{M})$ of thymol for $24 \mathrm{~h}$. Cell viability was not altered by thymol up to $30 \mu \mathrm{M}$, but $100 \mu \mathrm{M}$ and $200 \mu \mathrm{M}$ of thymol induced significant decreases in cell viability of $24.0 \pm 6.5$ and $54.2 \pm 3.5 \%$, respectively (Fig. 1B; $\mathrm{P}=0.0361$ and $\mathrm{P}<0.0001$, respectively). Therefore, all of the following experiments were performed using $30 \mu \mathrm{M}$ thymol or less.

Thymol suppresses C6 glioma cell migration. To determine whether thymol could inhibit the migration of FBS-stimulated glioma cells, a scratch wound healing assay was first performed. The cells were incubated in FBS-free medium for $24 \mathrm{~h}$ and then stimulated with $10 \% \mathrm{FBS}$ in the presence of different concentrations of thymol (3-30 $\mu \mathrm{M})$ for $24 \mathrm{~h}$. As shown in Fig. 2, $30 \mu \mathrm{M}$ thymol treatment caused a decrease in scratch wound healing compared with FBS treatment alone, whereas for other concentrations of thymol (3-10 $\mu \mathrm{M})$, the inhibition ratios indicated similar results to the untreated group. Next, in order to confirm the inhibitory effect of thymol on C6 glioma cell migration, a Boyden chamber assay was performed. Thymol $(30 \mu \mathrm{M})$ suppressed the FBS-stimulated migration of glioma cells over $90 \mathrm{~min}$. As shown in Fig. 3, FBS-stimulated C6 glioma cell migration was significantly inhibited by $30 \mu \mathrm{M}$ thymol $(\mathrm{P}=0.0001)$.

Effect of thymol on the phosphorylation of PKC $\alpha$ and $E R K 1 / 2$. To investigate the expression of protein markers for C6 glioma cell migration, the phosphorylation levels of PKC $\alpha$ and ERK1/2 were measured. As shown in Fig. 4, FBS-induced PKC $\alpha$ phosphorylation was not affected by 3 and $10 \mu \mathrm{M}$ thymol compared with the control. However, it decreased to $26.5 \pm 1.2 \%$, when the cells were treated with $30 \mu \mathrm{M}$ thymol (Fig. 4B; $\mathrm{P}<0.0001$ ). FBS induced-phosphorylation of ERK1/2 also showed a similar pattern, with no 
A
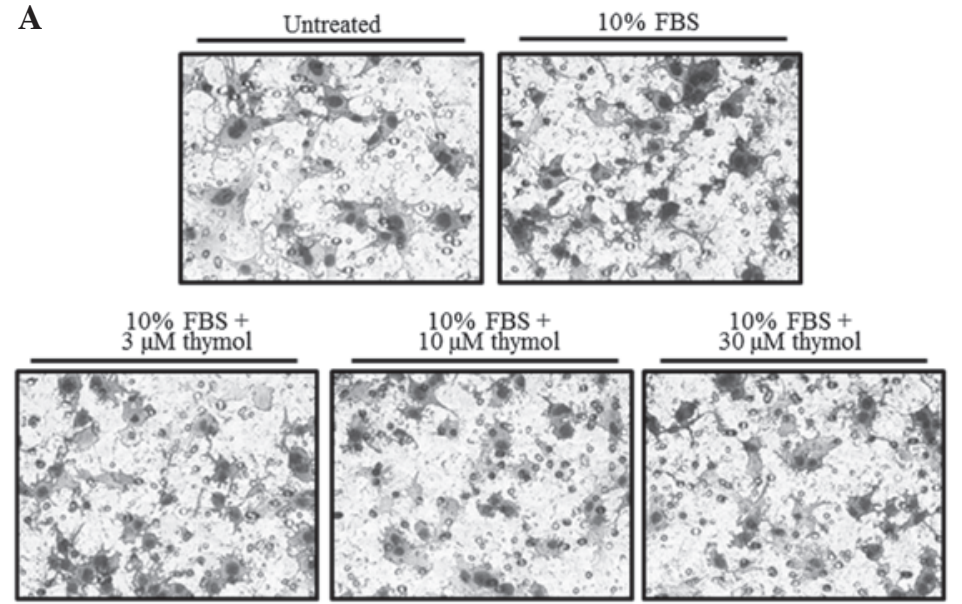

B

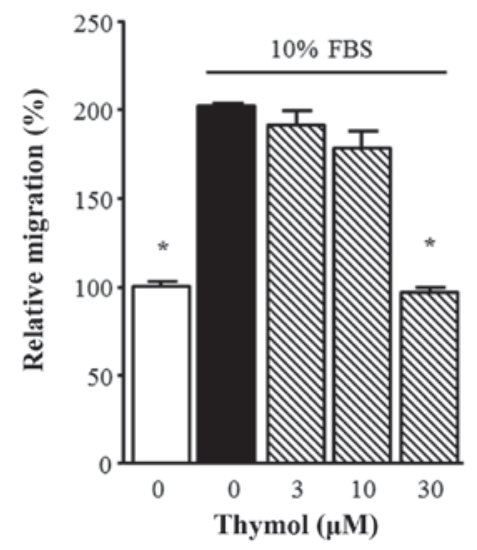

Figure 3. Effect of thymol treatment on FBS-stimulated C6 glioma cell migration. (A) C6 glioma cells were cultured in serum-free medium for 24 h. Cell migration was then tested in a Boyden chamber. The cells were incubated in the presence of thymol (3-30 $\mu \mathrm{M})$ with $10 \%$ FBS for 90 min. (B) The data represent the relative migration compared to the untreated control cells. Data are expressed as the mean \pm standad error $(\mathrm{n}=4)$. Untreated cell migration is expressed as $100 \%$. ${ }^{*} \mathrm{P}<0.05$ vs. FBS-stimulated cells (black bar). FBS, fetal bovine serum.

A

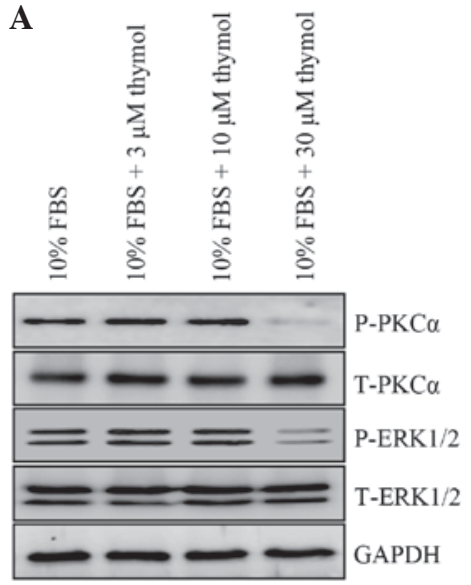

B

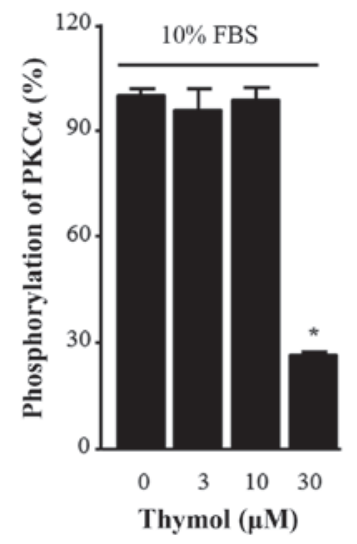

C

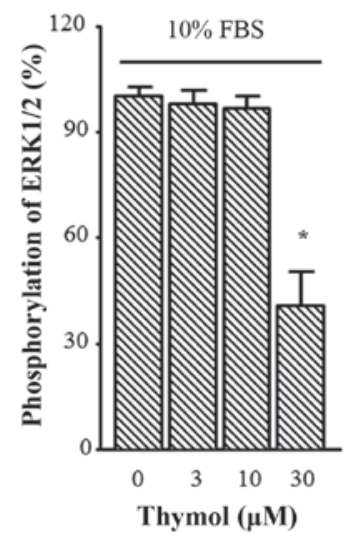

Figure 4. Western blot analysis of PKC $\alpha$ and ERK1/2 phosphorylation. (A) C6 glioma cells were cultured in serum-free medium for 24 h and then in the presence of thymol (3-30 $\mu \mathrm{M})$ for $1 \mathrm{~h}$, followed by exposure to $10 \%$ FBS for $24 \mathrm{~h}$. Cell lysates were separated by $12 \%$ polyacrylamide gel electrophoresis and the specific protein bands were labeled using antibodies. The band intensities were measured and reflect the effect of thymol on the phosphorylation of (B) PKC $\alpha$ and (C) ERK1/2. These values were normalized against total PKC $\alpha$ (T-PKC $\alpha$ ), total ERK1/2 (T-ERK1/2) and GAPDH. Data are expressed as the mean \pm standard error $(n=3)$. Cell response to FBS is expressed as $100 \%$. ${ }^{*} \mathrm{P}<0.05$ vs. FBS-stimulated cells in the absence of thymol. PKC $\alpha$, protein kinase C $\alpha$; ERK1/2, extracellular signal-regulated kinases 1/2; GAPDH, glyceraldehyde 3-phosphate dehydrogenase; FBS, fetal bovine serum.

change observed in response to 3 and $10 \mu \mathrm{M}$ thymol and a significant reduction observed in response to $30 \mu \mathrm{M}$ thymol (Fig. 4C; $\mathrm{P}=0.0044)$.

Effect of thymol on MMP9 and MMP2. To elucidate the inhibitory effect of thymol on the production of gelatinases in FBS-stimulated C6 glioma cells, the MMP9 and MMP2 levels were measured by western blotting (Fig. 5A). Thymol (30 $\mu \mathrm{M})$ decreased the expression of MMP9 and MMP2, whereas there was no change relative to the control when 3 and $10 \mu \mathrm{M}$ thymol was used (Fig. 5B and $\mathrm{C} ; \mathrm{P}=0.0012$ and $\mathrm{P}=0.0001$, respectively). Next, MMP activation was confirmed by gelatin zymography (Fig. 5D). The pattern of MMP secretion in the zymography assay was similar to that of the control group in response to 3 and $10 \mu \mathrm{M}$ thymol, but a significant reduction was observed in response to $30 \mu \mathrm{M}$ thymol (Fig. 5E and F; $\mathrm{P}=0.0001)$.

\section{Discussion}

The present study demonstrated that a natural monoterpenic phenol, thymol, inhibited the phosphorylation of ERK1/2 and PKC $\alpha$, reduced the expression of MMP2 and MMP9, and decreased the migration of the $\mathrm{C} 6$ glioma cells. The anticancer effect of thymol on various cancers has been reported (20-24). However, the effect of thymol on the motility of glioma cells has not yet been established. Malignant glioma has been reported as an incurable tumor and represents $\sim 50 \%$ of all brain tumors. Glioma is a highly invasive and lethal form of brain cancer, which is extremely difficult to treat via surgery or combined radiotherapy and chemotherapy (3). Consequently, the median patient survival time is limited to 12 months according to World Health Organization research (8). The relapse rate is extremely high and may lead to mortality, even with aggressive therapy. Although the strategy used in the 
A

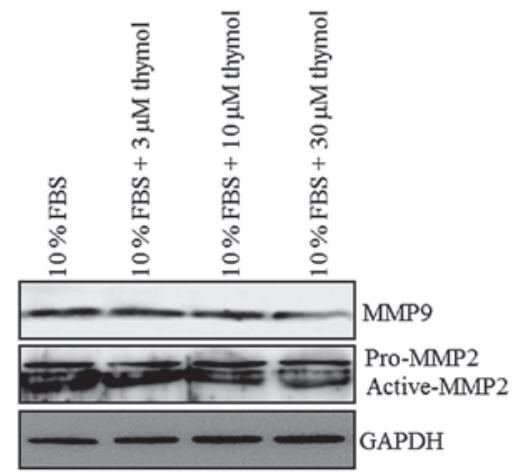

D

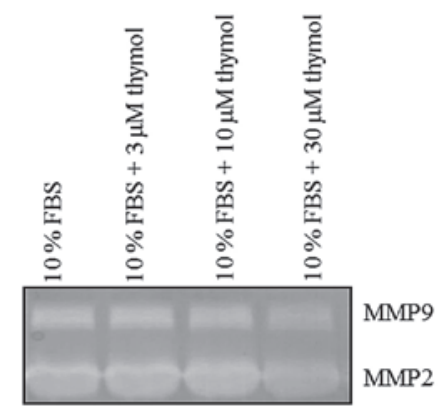

B

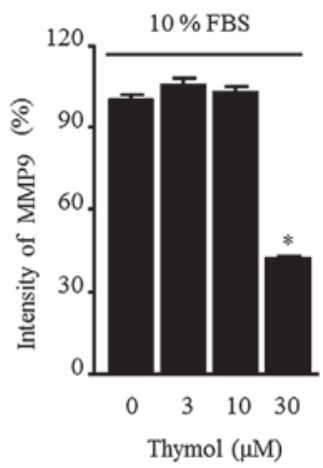

E

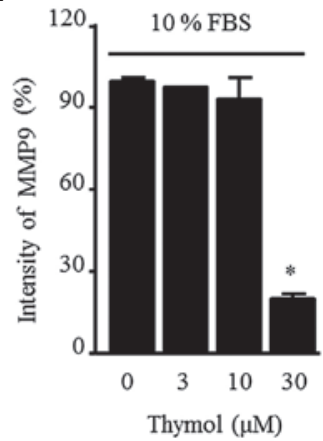

C

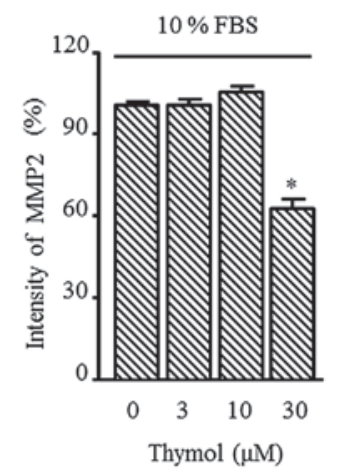

F

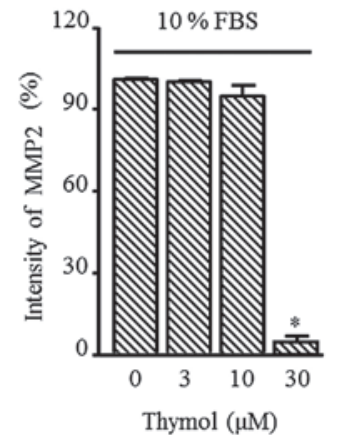

Figure 5. Effect of thymol on MMP2 and MMP9 activity in C6 glioma cells. (A) The C6 glioma cells were cultured in serum-free medium for 24 h and then in the presence of thymol (3-30 $\mu \mathrm{M})$ for $1 \mathrm{~h}$, followed by exposure to $10 \%$ FBS for $24 \mathrm{~h}$. Cell lysates were separated by $12 \%$ polyacrylamide gel electrophoresis and the specific protein bands were labeled using antibodies. The band intensities were measured and reflect the effect of thymol on (B) MMP9 and (C) activated MMP2. These values were normalized to GAPDH. (D) The harvested supernatants were also used for gelatin zymography assay. The band intensities were measured and reflect the effect of thymol on (E) MMP9 and (F) activated MMP2. Data are expressed as the mean \pm standard error ( $\mathrm{n}=3$ ). Cell response to FBS is expressed as $100 \%$. $^{*} \mathrm{P}<0.05$ vs. FBS-stimulated cells in the absence of thymol. MMP, matrix metalloproteinase; GAPDH, glyceraldehyde 3-phosphate dehydrogenase; FBS, fetal bovine serum.

present study is not a direct clinical method, this approach, in addition to those focusing on apoptosis or cell death, may prove useful for improving patient survival and slowing down cancer progression. Hence, we speculated that the inhibition of glioma cell migration could be a therapeutic strategy. Thus, a component from plant essential oils that could be effective for the treatment and, more importantly, the prevention of glioma was searched for. As a result, the present study was focused on thymol, which has been widely reported as a component of plant essential oils (18).

In the present study, the scratch wound healing and Boyden chamber assays were used to assess glioma migration. The results indicated that thymol inhibits FBS-induced C6 glioma cell migration. Furthermore, thymol significantly inhibited the phosphorylation of PKC $\alpha$ and ERK1/2, as well as the activation and expression of MMP9 and MMP2. PKC is an intracellular signaling protein of the protein kinase family that regulates cell survival, proliferation and differentiation, and the cell cycle (25-27). PKC phosphorylation is involved in malignant transformation and tumor promotion, as well as in invasion and metastasis. The high motility of glioma cells is key to the inability to manage the disease, preventing complete tumor removal and leading to therapeutic failure and recurrence (15). Moreover, elevated MMP2, which is regulated by $\mathrm{PKC}$, is tightly involved in glioma invasion (9). Notably, Tam et al studied the role of PKC $\alpha$ in cancer treatment and reported that it has been a major focus for various types of cancer and even cancer stem cells (28). In addition, Hu et al reported that activation of PKC $\alpha$ is also implicated in glioma cell migration (15). ERK1/2 also contributes to cell migration and proliferation in cancer cells $(29,30)$. Hence, the expression and phosphorylation of ERK1/2 was measured in the C6 glioma cells of the present study. The results showed that $30 \mu \mathrm{M}$ thymol attenuated ERK1/2 phosphorylation, but did not alter T-ERK1/2 expression. Recently, the role of ERK1/2 in the expression of the MMP family (MMP2 and MMP9) has been reported. MMP2 and MMP9 are also involved in tumor invasiveness and migration (10).

Taken together, the present results suggest that thymol inhibits glioma cell migration through PKC $\alpha$ and ERK1/2 phosphorylation, which consequently results in a decrease in MMP9 and MMP2 expression. The study indicates that thymol is a potential candidate for the treatment of malignant gliomas, as it reduces the FBS-induced motility of C6 glioma cells. The results of the present study shed light on the mechanism underlying the inhibitory effects of thymol on C6 glioma cell migration. Further studies are warranted to address whether the inhibitory effect of thymol on PKC $\alpha$ and ERK1/2 phosphorylation is associated with neuroprotective effects in normal cells.

\section{Acknowledgements}

The present study was supported by Konkuk University (Seoul, Republic of Korea) in 2015. 


\section{References}

1. Ostrom QT, Gittleman H, Fulop J, Liu M, Blanda R, Kromer C, Wolinsky Y, Kruchko C and Barnholtz-Sloan JS: CBTRUS statistical report: Primary brain and central nervous system tumors diagnosed in the United States in 2008-2012. Neuro Oncol 17 (Suppl 4): iv1-iv62, 2015.

2. Ostrom QT, Bauchet L, Davis FG, Deltour I, Fisher JL, Langer CE, Pekmezci M, Schwartzbaum JA, Turner MC, Walsh KM, et al: The epidemiology of glioma in adults: A "state of the science" review. Neuro Oncol 16: 896-913, 2014.

3. Belda-Iniesta C, de Castro Carpeño J, Casado Sáenz E, Cejas Guerrero P, Perona R and González Barón M: Molecular biology of malignant gliomas. Clin Transl Oncol 8: 635-641, 2006

4. Coniglio SJ and Segall JE: Review: Molecular mechanism of microglia stimulated glioblastoma invasion. Matrix Biol 32: 372-380, 2013.

5. Qi ST, Liu Y, Pan J, Chotai S and Fang LX: A radiopathological classification of dural tail sign of meningiomas. J Neurosurg 117: 645-653, 2012.

6. Hess KR, Broglio KR and Bondy ML: Adult glioma incidence trends in the United States, 1977-2000. Cancer 101: 2293-2299, 2004.

7. Chinot OL, Macdonald DR, Abrey LE,Zahlmann G, Kerloëguen Y and Cloughesy TF: Response assessment criteria for glioblastoma: Practical adaptation and implementation in clinical trials of antiangiogenic therapy. Curr Neurol Neurosci Rep 13: 347, 2013.

8. Le DM, Besson A, Fogg DK, Choi KS, Waisman DM, GoodyerCG, Rewcastle B and Yong VW: Exploitation of astrocytes by glioma cells to facilitate invasiveness: A mechanism involving matrix metalloproteinase- 2 and the urokinase-type plasminogen activator-plasmin cascade. J Neurosci 23: 4034-4043, 2003.

9. Uhm JH, Dooley NP, Villemure JG and Yong VW: Glioma invasion in vitro: Regulation by matrix metalloprotease- 2 and protein kinase C. Clin Exp Metastasis 14: 421-433, 1996.

10. Glassmann A, Reichmann K, Scheffler B, Glas M, Veit N and Probstmeier R: Pharmacological targeting of the constitutively activated MEK/MAPK-dependent signaling pathway in glioma cells inhibits cell proliferation and migration. Int J Oncol 39: 1567-1575, 2011.

11. Soletti RC, Alves T, Vernal J, Terenzi H, Anderluh G, Borges HL, Gabilan NH and Moura-Neto V: Inhibition of MAPK/ERK, PKC and CaMKII signaling blocks cytolysin-induced human glioma cell death. Anticancer Res 30: 1209-1215, 2010.

12. Strnisková M, Barancík M and Ravingerová T: Mitogen-activated protein kinases and their role in regulation of cellular processes. Gen Physiol Biophys 21: 231-255, 2002.

13. Chen CM, Hsieh YH, Hwang JM, Jan HJ, Hsieh SC, Lin SH and Lai CY: Fisetin suppresses ADAM9 expression and inhibits invasion of glioma cancer cells through increased phosphorylation of ERK1/2. Tumour Biol 36: 3407-3415, 2015.

14. Mendes O, Kim HT, Lungu G and Stoica G: MMP2 role in breast cancer brain metastasis development and its regulation by TIMP2 and ERK1/2. Clin Exp Metastasis 24: 341-351, 2007.

15. Hu JG, Wang XF, Zhou JS, Wang FC, Li XW and Lü HZ: Activation of PKC-alpha is required for migration of C6 glioma cells. Acta Neurobiol Exp (Wars) 70: 239-245, 2010.

16. Köhrmann A, Kammerer U, Kapp M, Dietl J and Anacker J: Expression of matrix metalloproteinases (MMPs) in primary human breast cancer and breast cancer cell lines: New findings and review of the literature. BMC Cancer 9: 188, 2009.
17. Khasigov PZ, Podobed OV, Gracheva TS, Salbiev KD, Grachev SV and Berezov TT: Role of matrix metalloproteinases and their inhibitors in tumor invasion and metastasis. Biochemistry (Mosc) 68: 711-717, 2003.

18. Undeğer U, Başaran A, Degen GH and Başaran N: Antioxidant activities of major thyme ingredients and lack of (oxidative) DNA damage in V79 Chinese hamster lung fibroblast cells at low levels of carvacrol and thymol. Food Chem Toxicol 47: 2037-2043, 2009

19. Grommes C, Landreth GE, Sastre M, et al: Inhibition of in vivo glioma growth and invasion by peroxisome proliferatoractivated receptor gamma agonist treatment. Mol Pharmacol 70:1524-1533, 2006.

20. Deb DD, Parimala G, Saravana Devi S and Chakraborty T: Effect of thymol on peripheral blood mononuclear cell PBMC and acute promyelotic cancer cell line HL-60. Chem Biol Interact 193: 97-106, 2011.

21. Chang HT, Hsu SS, Chou CT, Cheng JS, Wang JL, Lin KL, Fang YC, Chen WC, Chien JM, Lu T, et al: Effect of thymol on $\mathrm{Ca}^{2+}$ homeostasis and viability in MG63 human osteosarcoma cells. Pharmacology 88: 201-212, 2011.

22. Hsu SS, Lin KL, Chou CT, Chiang AJ, Liang WZ, Chang HT, Tsai JY, Liao WC, Huang FD, Huang JK, et al: Effect of thymol on $\mathrm{Ca} 2+$ homeostasis and viability in human glioblastoma cells. Eur J Pharmacol 670: 85-91, 2011.

23. Kang SH, Kim YS, Kim EK, et al: Anticancer Effect of Thymol on AGS Human Gastric Carcinoma Cells. J Microbiol Biotechnol 26: $28-37,2016$.

24. Archana PR, Nageshwar Rao B and Satish Rao BS: Modulation of gamma ray-induced genotoxic effect by thymol, a monoterpene phenol derivative of cymene. Integr Cancer Ther 10: 374-383, 2011.

25. Carduner L, Picot CR, Leroy-Dudal J, Blay L, Kellouche S and Carreiras F: Cell cycle arrest or survival signaling through $\alpha v$ integrins, activation of PKC and ERK1/2 lead to anoikis resistance of ovarian cancer spheroids. Exp Cell Res 320: 329-342, 2014.

26. Kim H, Zamel R, Bai XH and Liu M: PKC activation induces inflammatory response and cell death in human bronchial epithelial cells. PLoS One 8: e64182, 2013.

27. Hartleben B, Widmeier E, Suhm M, Worthmann K, Schell C, Helmstädter M, Wiech T, Walz G, Leitges M, Schiffer M and Huber TB: APKC $\lambda / \mathrm{l}$ and $\mathrm{aPKC} \zeta$ contribute to podocyte differentiation and glomerular maturation. J Am Soc Nephrol 24: 253-267, 2013.

28. Tam WL, Lu H, Buikhuisen J, Soh BS, Lim E, Reinhardt F, Wu ZJ, Krall JA, Bierie B, Guo W, et al: Protein Kinase C $\alpha$ is a central signaling node and therapeutic target for breast cancer stem cells. Cancer Cell 24: 347-364, 2013.

29. Li Q, Fu GB, Zheng JT, He J, Niu XB, Chen QD, Yin Y, Qian X, Xu Q, Wang M, et al: NADPH oxidase subunit p22 (phox)-mediated reactive oxygen species contribute to angiogenesis and tumor growth through AKT and ERK1/2 signaling pathways in prostate cancer. Biochim Biophys Acta 1833: 3375-3385, 2013

30. Sun J, Liu SZ, Lin Y, Cao XP and Liu JM: TGF- $\beta$ promotes glioma cell growth via activating Nodal expression through Smad and ERK1/2 pathways. Biochem Biophys Res Commun 443: 1066-1072, 2014 